\title{
Long-Term Surgical Complications in the Oral Cancer Patient: a Comprehensive Review. Part I
}

\author{
Antonia Kolokythas \\ Department of Oral and Maxillofacial Surgery, University of Illinois at Chicago, Chicago, USA
}

\author{
Corresponding Author: \\ Antonia Kolokythas \\ Department of Oral and Maxillofacial Surgery/Multidisciplinary Head and Neck Cancer Clinic \\ University of Illinois at Chicago \\ 801 S. Paulina Street, MC 835, Chicago, IL, 60612-7210 \\ USA \\ Phone: $312-996-1052$ \\ Fax: 312-996-5987 \\ E-mail: ga1@uic.edu
}

\begin{abstract}
Objectives: Oral and oropharyngeal cancer remains among the top ten most common malignancies in the United States and worldwide. Over the last several decades the approach to treatment of oral cancer has changed very little with regards to primary tumour extirpation while the approach to the "at risk" lymph nodes has evolved significantly. Perhaps the most significant change in the surgical treatment of cancer is the introduction of free flap for reconstruction post resection. Despite these surgical advances, oral cancer ablation, still results in the sacrifice of several functional and aesthetic organs. The aim of this article was to provide a comprehensive review of the potential long-term complications associated with surgical treatment of oral cancer and their management.

Material and Methods: The available English language literature relevant to long-term surgical complications associated with surgical treatment of oral cancer was reviewed. The potential common as well as rarer complications that may be encountered and their treatment are summarized.

Results: In total 50 literature sources were obtained and reviewed. The topics covered in the first part of this review series include ablative surgery complications, issues with speech, swallowing and chewing and neurologic dysfunction.

Conclusions: The early complications associated with oncologic surgery for oral cancer are similar to other surgical procedures. The potential long-term complications however are quite challenging for the oncologic team and the patient who survives oral cancer, primarily due to the highly specialized regional tissues involved in the surgical field.
\end{abstract}

Keywords: oral cancer; oropharyngeal cancer; postoperative complications; neurologic dysfunction; speech disorders; swallowing disorders.

\section{Accepted for publication: 4 July 2010}

To cite this article:

Kolokythas A. Long-Term Surgical Complications in the Oral Cancer Patient: a Comprehensive Review. Part I.

J Oral Maxillofac Res 2010 (Jul-Sep);1(3):e1

URL: http://www.ejomr.org/JOMR/archives/2010/3/e1/e1ht.pdf

doi: $10.5037 /$ jomr.2010.1301 


\section{INTRODUCTION}

Oral and oropharyngeal cancer remains among the top ten most common malignancies in the United States, Europe, and worldwide [1]. Over the last several decades approach to treatment of oral cancer has changed very little with regards to primary tumour extirpation, with the exception of marginal mandibular resection. On the contrary major changes in the approach to cervical lymph nodes at risk for metastasis have been implemented based on our better understanding of lymphatic drainage. The radical neck dissection, once advocated by Dr. Crile [2] as the only upfront treatment for head and neck cancer, is now rarely if ever performed and mainly reserved for specific cases. Also, the ability to offer a variety of reconstruction options with the available hardware, local and regional flaps, as well as composite free tissue transfer, has contributed to the overall significant improvements in functional and aesthetic outcomes. The head and neck cancer survivor today does not necessarily have to leave with devastating disfigurement, speech and swallowing impairment. Despite these surgical advances, the ablative process still results in the sacrifice of several functional and aesthetic organs during surgery for cancer of the oral cavity [3]. Early complications from ablative surgery for oral cancer are, for the most part, similar to those from other sites. The potential long-term complications however are quite challenging for the oncologic team as well as the patient who survives oral cancer, primarily due to the highly specialized regional tissues involved in the surgical field $[4,5]$.

The aim of the present article was to provide a comprehensive review of the potential long-term complications associated with surgical treatment of oral cancer and their management. The topics covered in the first part of this review series include ablative surgery complications, issues with speech, swallowing and chewing and neurologic dysfunction.

\section{MATERIAL AND METHODS}

Literature was selected through a search of PubMed, Embase and Cochrane Central Register electronic databases. The keywords used for search were oral cancer, oral surgical procedure, postoperative complications, neurologic dysfunction, speech disorders and swallowing disorders. The search was restricted to English language articles, and books published from March 1962 to June 2010. The included publications were relevant to long-term surgical complications associated with surgical treatment of oral cancer.
The potential common as well as rarer complications that may be encountered and their treatment are summarized.

The topics covered in the first part of this review series include ablative surgery complications, issues with speech, swallowing and chewing and neurologic dysfunction.

\section{Cancer resection: complications with eradication of disease}

Failure to cure

Failure to cure the disease remains the most significant and devastating negative outcome for the cancer patient and the treating team. Persistent disease, local or regional recurrence, distant metastasis, or presence of second primary cancer are among the commonest reasons for failure (Figures 1-4). The vast majority of recurrences occur within the first 2 to 3 years following completion of treatment [1-3]. Local recurrences are mainly the result of failure to eradicate the primary cancer with surgery and are often associated with failure to achieve negative surgical margins. In 1953 Slaughter [6] put emphasis on the significance of examining healthy appearing tissues surrounding the tumour for risk assessment and disease control. In general, the head and neck surgeon attempts to remove the primary cancer with a 1.0 to $1.5 \mathrm{~cm}$ margin of "healthy looking" tissue, if anatomically allowed, in order to achieve histopathologically "negative margins". Throughout the literature there is tremendous debate with regards to what precisely is considered a "negative margin". From a histopathologic point of view lack of dysplasia, carcinoma in situ or invasive cancer within $5 \mathrm{~mm}$ of the resection margins of the pathologic specimen is reported as "negative margin". However, the validity of this interpretation and its association with local recurrence has been challenged in various studies. The lack of universally accepted standardized terms and definitions as well as clear distinction between mucosal and deep margins has been identified as a major deficit when the status of the margins is examined [2, 7-9].

In an attempt to ensure adequate tumour resection, surgeons traditionally submit frozen tissue sections for examination prior to closure or reconstruction. These have been proven valuable when found positive for disease, and thus additional tissue resection is undertaken [10]. Diagnostic accuracy of frozen tissue specimens has been reported to be between $96 \%$ and $98 \%$. "Sampling error", inability to perform frozen sections to examine for bone involvement, and difficulties with interpretation of histological changes in radiated tissues are a few of the limitations that contribute to the lack of reliability of frozen sections $[\underline{11}, \underline{12}]$. 


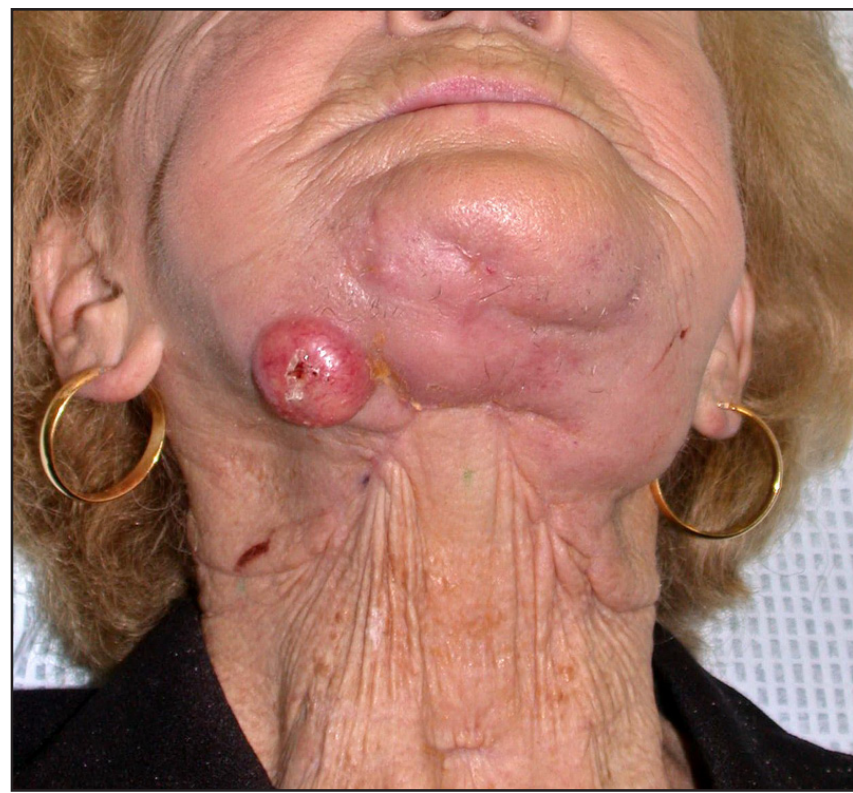

Figure 1. Local failure with extraoral tumour extension.

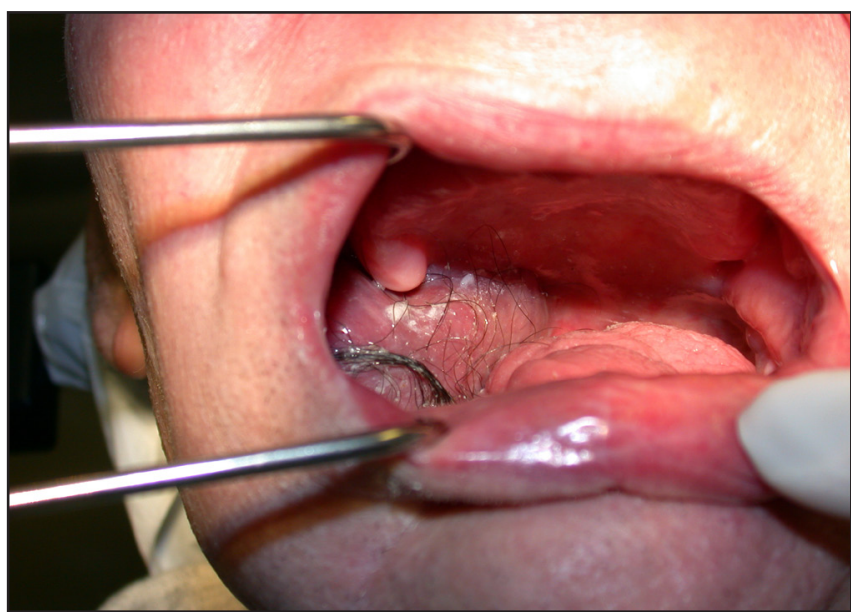

Figure 2. Local Failure under existing pectoralis major myocutaneous flap.

Studies that have evaluated frozen section status, and the status of the resection margins, have demonstrated a clear association between positive margins of frozen sections and local failures. Recent advances in molecular biology of oral cancer, with the acceptance of field cancerization, and multicentricity along with primary tumour characteristics, may explain, at least in part, the difficulties with achieving local control [르,13-16]. The benefit of removing the "at risk" lymph nodes of the neck in advanced stage (T3 and T4) tumours has been clearly demonstrated and is generally widely accepted. Eradication or prevention of neck disease is undertaken in the form of surgery via neck dissection, or with the addition of radiation or chemotherapy. Controversy still exists as to whether one should treat or watch the neck nodes in early stage tumours with no clinical or radiographic evidence of nodal metastasis (N0 neck). This is an important issue clinically, since

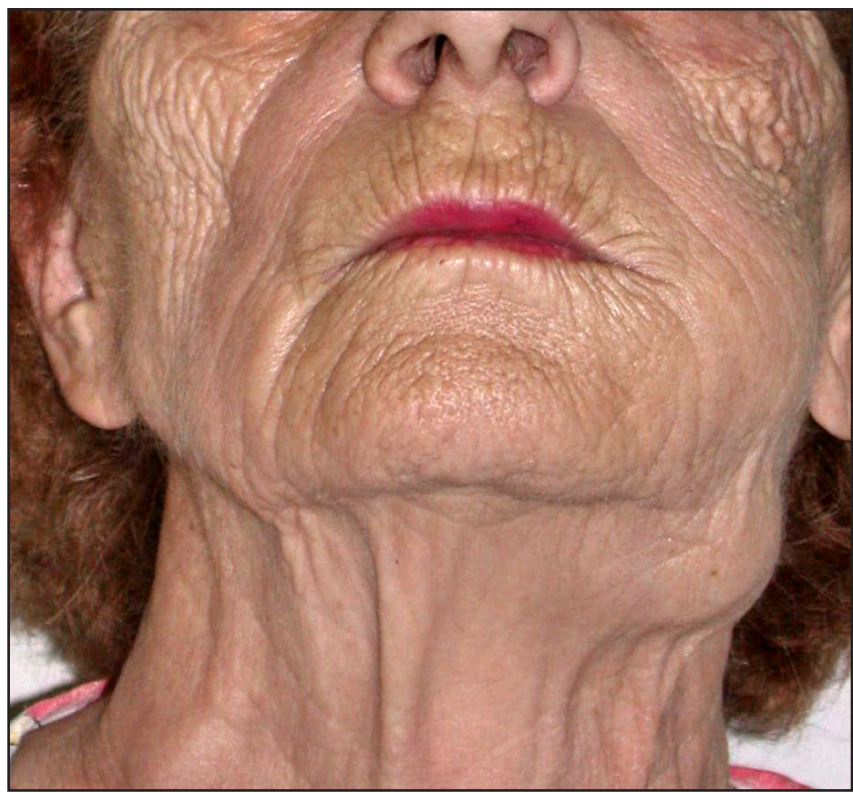

Figure 3. Regional failure left neck post treatment.

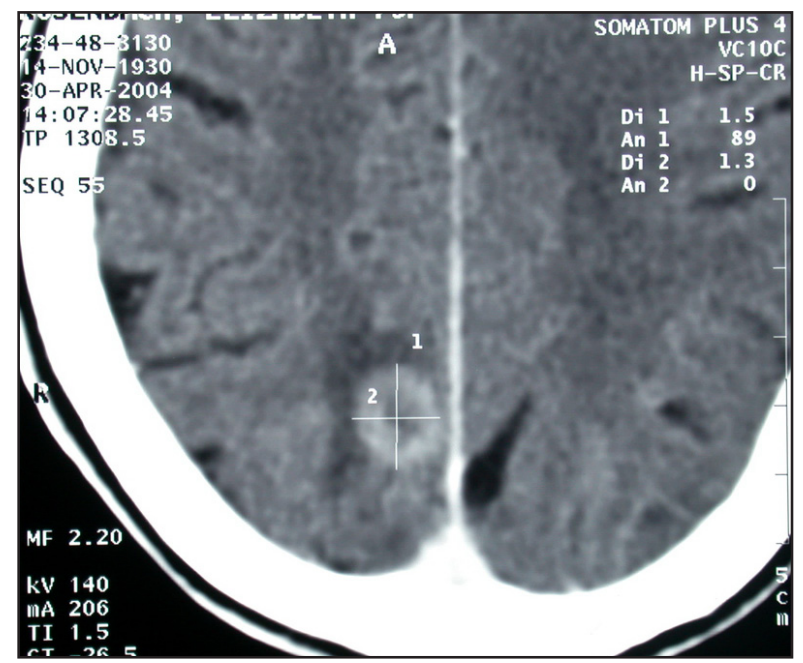

Figure 4. Brain metastasis.

metastasis to the cervical lymph nodes has been shown to be a significant negative predictor of outcome and is associated with tumour aggressiveness dropping survival by 50 percent $[\underline{3}, 14,17-20]$.

A follow-up protocol is usually proposed by the treating team for all cancer patients; this recall includes frequent clinical examinations and periodic radiographic surveillance, with computed tomography or magnetic resonance imaging. Both imaging modalities have been proven to be sensitive tests for assessing disease status. Most recently positron emission tomography (PET), with or without computed tomography and magnetic resonance imaging, has been used for surveillance for local and regional tumour recurrence. The advantage of the PET is that it may assist in the differentiation of postsurgical scarring and postradiation treatment changes from tumour recurrence if obtained at a reasonable time after completion of treatment. 
The majority of oncology teams usually wait at least 6 weeks and preferably 3 months post treatment completion to obtain imaging for evaluation of response $[21,22]$. Despite all current advances in diagnosis and treatment modalities, local and regional failures in oral cancer remain problematic issues.

In a non-radiated field, local and regional failure may be treated with additional surgery alone, or in combination with radiation and chemotherapy. One of the major clinical challenges is the case of local and or regional failure following appropriate radiation treatment (Figure 5). It is best to treat these patients with additional surgery whenever feasible. If surgery is not possible, then additional radiation may be of use, but it is associated with serious complications and poor overall long-term therapeutic results [23-26]. Another major problem with these patients who fail surgery and chemo-radiation therapy is the presence of distant metastasis. This finding significantly decreases the chances of disease control and impacts negatively on the life expectancy of the patient. Recent studies have demonstrated that although local and regional control is achieved with current multimodal treatment, distant metastasis has significantly increased [14]. As new chemotherapeutic agents and combination therapies become available clinically, a delay in the progression of advanced disease may become a more reasonable expectation in the future [27-29]. Furthermore since there are several ongoing clinical trials, patients with persistent disease or recurrence after adequate treatment should be evaluated for enrolment. In addition to the potential direct benefits to the patient, the knowledge gained from these trials along with ongoing research could assist in development of new approaches.

\section{Cancer resection: effects on speech, swallowing and chewing \\ Speech and swallowing}

Surgical resection of cancers in the oral cavity impacts on the two most important functions of the organs involved: speech and swallowing. More specifically, the oral preparatory phase (formation of a bolus) and the oral phase of normal deglutition, can be significantly impaired following tumour ablation. Loss of a significant portion of the tongue will limit the ability to transfer food into the appropriate position for grinding by the dentition. Therefore, the first phase of swallowing is disrupted. The transfer of the bolus from the anterior portion of the oral cavity to the area of the tonsillar pillars, where the initiation of the swallowing reflex occurs, constitutes the second phase of swallowing. The harmonious coordination of the lips, tongue, buccal mucosa and maxillomandibular complex is required for

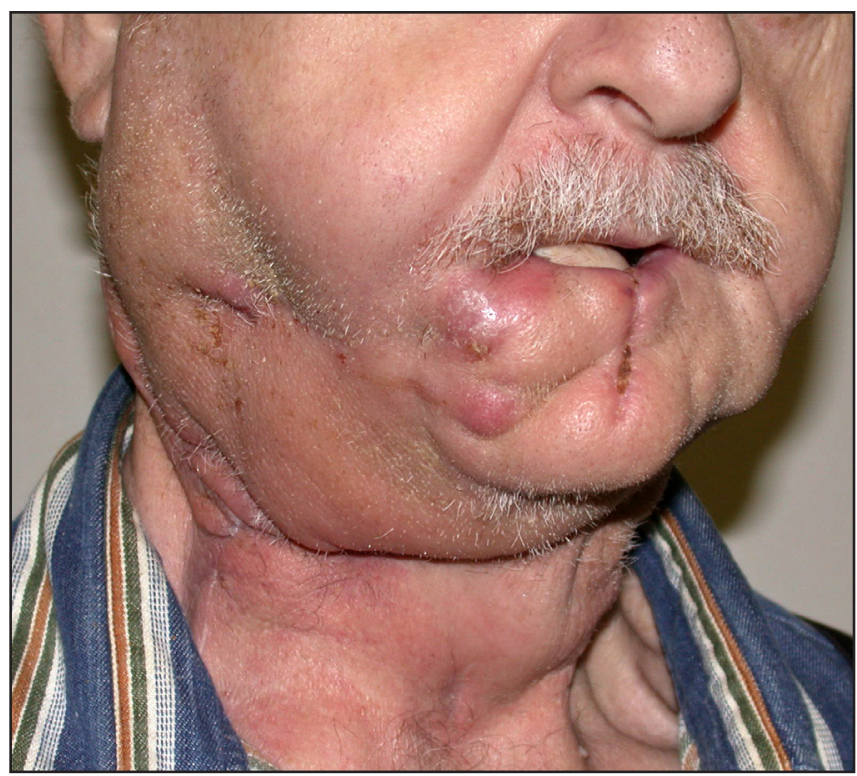

Figure 5. Persistent disease during radiation and chemotherapy.

completion of these phases and progression to the pharyngeal phases of swallowing. The same structures are associated with speech production and more specifically articulation. As a general rule, ablative surgery that involves the most anterior portion of the oral tongue is associated with significantly altered speech, while resections that incorporate the posterior tongue affect swallowing. As postsurgical time progresses, surgical site scaring and fibrosis, along with xerostomia from adjunctive radiotherapy, further impairs speech and swallowing [30-33].

The complexity of the function of the oral cavity structures cannot always be restored to their presurgical status despite use of swallowing manoeuvres and sensate free tissue transfer. Difficulties with articulation, chewing and swallowing could become long-term problems for these patients, and adequate rehabilitation and support should be initiated early. Consultations with speech and swallowing services are imperative in assisting the patient to regain their pretreatment status and possibly avoid long-term dependence on gastric tubes, recurrent aspiration, and communication difficulties [33-35].

\section{Masticatory function and nutrition}

Masticatory function is adversely influenced by the surgical management of oral cancer. The tongue, floor of mouth, maxilla and mandible with the adjacent tissues are vital structures used for mastication and their anatomic and functional integrity is altered during ablative surgery. For efficient mastication all three components of mastication (manipulation, trituration, and consolidation) are required, and are the result of synchronous interaction of hard and soft tissues [36]. 
Mandibular or maxillary resection affects the grinding ability either due to loss of stable and reproducible stomatognathic system relationships or due to loss of tooth-to-tooth contacts and diminished biting forces. In addition, loss of soft tissue bulk and sensation causes difficulties with the patient's ability to manipulate the food bolus to the occlusal table, retrieve the bolus, and then consolidate it prior to deglutition.

Numerous studies have evaluated the limitations associated with mastication status post cancer resection and the effects of reconstruction on masticatory function. Biting force testing, and those evaluating the tongue and cheek function, could be employed to evaluate the specific aspects of mastication. In addition patient questionnaires are used to access the overall efficiency in masticating food and the quality of life following mandibular resection with respect to success of reconstruction utilization. Unfortunately, significant variability in the testing instruments utilized in these studies, has resulted in conflicting results and conclusions [37,38]. It is universally accepted that reconstruction of defects in the oral cavity, at the minimum results in decreased scar formation and reduced associated functional and cosmetic limitations. Soft tissue reconstruction with a pedicle flaps and the use of reconstruction plates to span bony continuity defects has been shown to be superior to simple closure techniques alone. With the availability of free tissue transfer, composite flaps can restore not only tissue bulk and facial aesthetics, but address masticatory function due to the potential for future dental rehabilitation $[\underline{39}, \underline{40}]$.

Limited interocclusal opening, less than $35 \mathrm{~mm}$ between the maxillary and mandibular incisors, is one cause of trismus based on the restrictions in mouth opening and mandibular function perceived by the patients. Trismus (restricted mouth opening) is a common complaint following oral cancer surgery. Fibrosis and scar contraction, in addition to contraction of the muscles of mastication, are the main reasons for inability of the patient to open the mouth. Common oral cancer procedures resulting in trismus include maxillary surgery involving the origin of the medial and lateral pterygoid muscles from the pterygoid plates, or mandibulectomy procedures involving any of the muscles of mastication, including the temporal muscle insertion to the coronoid process, the masseter muscle insertion to the mandibular angle and ramus, and the pterygoid insertions to the medial ramus and condylar neck. Of course, adjuvant radiotherapy may lead to fibrotic changes which may exacerbate the magnitude of surgically-induced trismus. Finally, disarticulation of the temporomandibular joint for tumour eradication will certainly lead to similar limited mouth opening.
Exercise regimens, and mouth opening assisting devices, either active or passive, are regularly prescribed to assist these patients. Unfortunately, if these steps are not incorporated early, before severe scarring has occurred, and maintained long-term, only limited improvement in trismus can be expected [41-44]. As a result, the presence of these difficulties with mastication, swallowing, trismus, along with utilization of bulky tissue for coverage of defects that do not always address the functional needs of the cancer patient all contribute to limitations in food intake and compromise the nutritional status of patients. A significant number of these patients are forced to adapt specific diet modifications that may lead to nutritional deficits. The usual problems are inadequate protein intake and frequent episodes of dehydration, and some patients become dependent on feeding formulas through gastric tubes. Although these formulations are appropriately balanced with adequate calories, issues of intolerance, diarrhea, dehydration and electrolyte imbalance are very common. Nutritional education and support, along with close monitoring of the caloric and nutritional intake of these patients, will assist in preventing longterm deficits and frequent hospital admissions $[45,46]$. Additionally, the patient population with oral cancer may have a social history significant for alcohol abuse, and preexisting nutritional deficiencies, and this may impact on continued malnutrition as well as poor wound healing postoperatively.

\section{Cancer resection: neurologic complications}

Several cranial nerves are at risk during resection of primary tumours as well as neck dissection for removal of "at risk" or involved lymph nodes. Tumour size and location as well as the extent of neck disease if present, often necessitate cranial nerves directly involved or in close proximity to be sacrificed. Furthermore the approaches often required to access and ensure adequate tumour resection can endanger integrity of the cranial nerves in the vicinity (Table 1).

Table 1. Cranial nerves at risk for postsurgery dysfunction

1. Spinal accessory nerve

2. Phrenic nerve

3. Hypoglossal nerve

4. Lingual nerve

5. Vagus nerve

i) Recurrent laryngeal nerve

ii) Superior laryngeal nerve

6. Sympathetic trunk

7. Marginal mandibular branch of facial nerve 


\section{Spinal accessory nerve}

There are several nerves at risk for iatrogenic injury during extirpative surgery in the head and neck due to their anatomic proximity to the surgical field, especially when the surgery involves neck dissection. Nodal metastasis has long been considered an ominous sign in head and neck cancer, and radical resection of the cervical lymph nodes, with adjacent muscles, vessels and nerves was advocated. This was based upon the same principles applied in breast cancer surgery, and it was considered the primary method of managing this disease process. This type of radical surgery was accompanied by serious postoperative functional and aesthetic complications.

Shoulder pain and spinal accessory nerve dysfunction are reasons to that have led surgeons to consider less aggressive surgical techniques to manage cervical nodal metastasis in the head and neck cancer patient. Nerve preservation is not synonymous with nerve function preservation, and "shoulder syndrome" can develop even when the spinal accessory nerve is not sacrificed. Pain, muscle weakness, shoulder movement restraint, deformity and inability to abduct the upper extremity above 90 degrees are the results of denervation of the trapezius muscle. Transection of the eleventh cranial nerve during radical surgery, or excessive manipulation during less radical procedures, as well as severing the anastomosis with the cervical plexus, may all result in this complication.

Some debate exists in the literature regarding the actual incidence of developing shoulder syndrome even after preserving the spinal accessory nerve. All studies have clearly demonstrated that when the nerve trunk and its anastomosis with the cervical plexus are preserved, patients have better postoperative function and significantly less pain and deformity. Careful dissection around the vicinity of the nerve, limited use of electrocautery, and early identification based on known anatomical landmarks, may help to limit surgically-induced neural trauma.

Direct primary anastomosis of the iatrogenically severed nerve is possible, and has been described in the literature, however, there are no available techniques to restore the aesthetic component of "shoulder syndrome", but aggressive immediate physical therapy can improve functional outcomes $[\underline{2}, \underline{47}, \underline{48}]$.

\section{Marginal mandibular branch of the facial nerve}

The marginal mandibular branch of the facial nerve (C.N. VII) is at risk during incision and elevation of the flaps for standard neck dissections, and access to the oral cavity for composite resections. The nerve runs at the under surface of the platysma muscle and is superficial to the facial vein at the submandibular gland region. Dingman and Grabb in 1962 [49] have described the anatomic location of this nerve, with a position superior to the inferior border of the mandible in $81 \%$ of cadavers proximal to the facial vessels, and in $100 \%$ of specimens distal to the facial vessels.

On occasion, it may be more hazardous to dissect and mobilize the nerve so that the facial vein can be used to retract it away from the surgical field. Nodal dissection around the facial vessel, however, is not compromised with this surgical manoeuvre.

Injury to this nerve causes alteration of the mobility of the corner of the mouth due to disruption of the innervation to the orbicularis oris and depressor anguli oris muscles. In addition to the functional disturbance, transection of this branch has adverse cosmetic consequences. Inability to control the movement of the lower lip can interfere with liquid consumption, and gives the patient the appearance of having sustained an injury similar to a cerebrovascular accident (Figure 6). Careful planning of the incisions, taking into consideration the route of the nerve and identification early during flap elevation, is the best way of preventing inadvertent iatrogenic injury to this branch of the facial nerve. Some functionality is normally restored if the neurologic injury is due to traction and not severance of the nerve, but it may take several months for spontaneous neurosensory recovery [2]

\section{Phrenic nerve}

Another neurologic complication that may be encountered during neck dissection is injury to the phrenic nerve. This causes paralysis to the ipsilateral

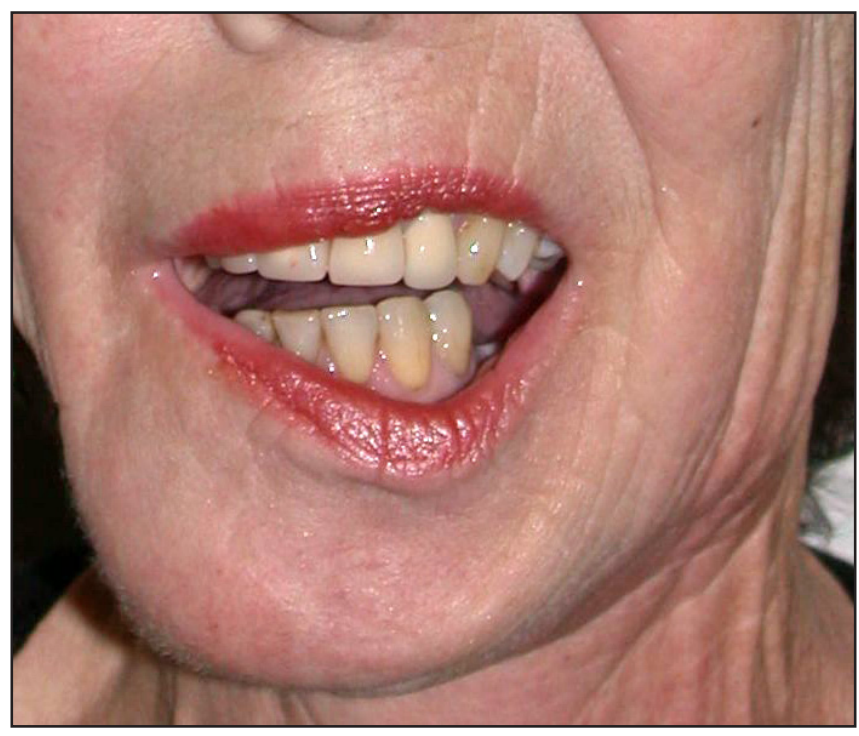

Figure 6. Dysfunction of right marginal mandibular nerve evident upon animation. 
diaphragm since the phrenic nerve is the only motor innervation to this muscle. The diaphragm is responsible for $70 \%$ of the respiratory movement and long-term pulmonary complications can originate from this type of injury.

An attempt to limit the surgical dissection to a layer superficial to the pre-vertebral fascia, with identification of the nerve, may assist surgeons in preventing this complication $[2,50]$.

\section{Hypoglossal and lingual nerves}

The hypoglossal nerve (C.N. XII) provides motor innervation to the ipsilateral tongue, and the lingual nerve (C.N. V3) provides sensation and taste innervation, via the chorda tympani branch of the facial nerve (C.N. VII), to the anterior $2 / 3$ of the ipsilateral tongue. Both nerves may be injured iatrogenically during neck dissection, and excision of the tongue and floor of mouth may further endanger the lingual nerve. Unless there is gross neural invasion by the cancer, or the path of the nerve runs directly through the tumour, both nerves are usually preserved. Hypoglossal nerve dysfunction can present with subclinical symptoms with deviation of the tongue to the ipsilateral side of injury, accidental tongue biting, and dysarthria (Figure 7). Patients may also experience an exaggeration of their difficulties with mastication and deglutition that are already present following surgery. In cases of bilateral hypoglossal nerve injury, upper airway obstruction can occur when the patient is placed in a supine position. Additionally, atrophy of the muscles of the tongue can occur and add to the functional difficulties experienced by these patients.

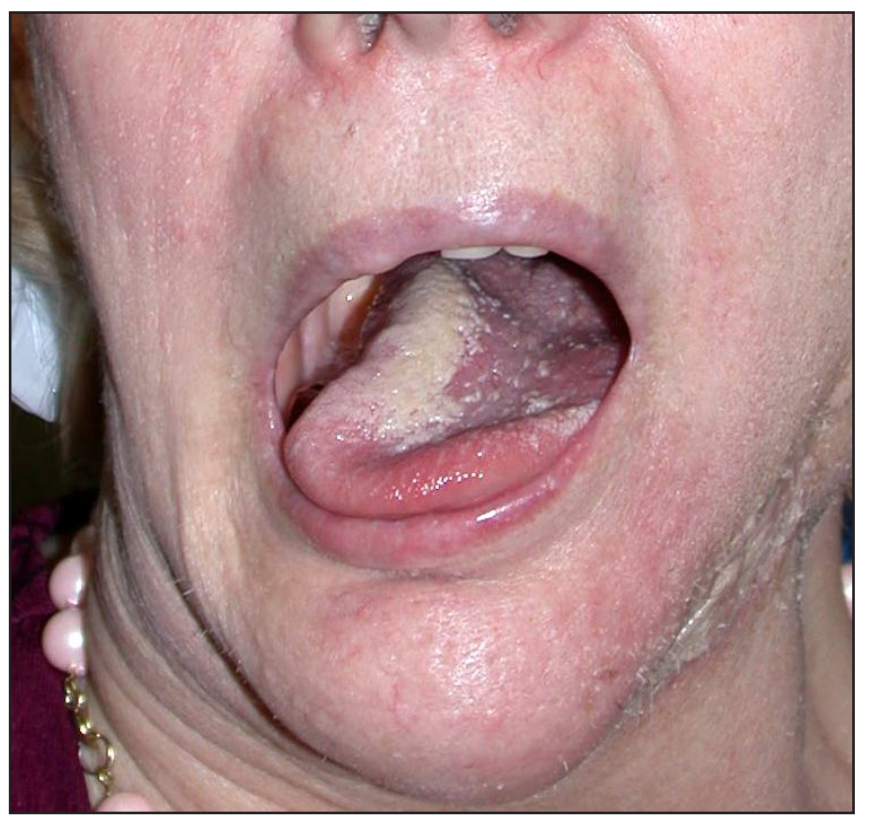

Figure 7. Right hypoglossal nerve dysfunction.
Ipsilateral loss of sensation to the tongue from lingual nerve injury can further impact on the difficulties with mastication, speech, swallowing and injury to the tongue during speech and mastication. These injuries can occur from traction or dissection around the lingual nerve during surgery, and may not always be recognized until later in the postoperative course. A compromised ability to taste foods due to chorda tympani nerve injury may also contribute to decreased food intake and malnutrition. Rehabilitation for speech and swallowing, using physical therapy is usually beneficial for these patients $[\underline{2}, \underline{50}]$.

\section{Vagus, recurrent laryngeal and superior laryngeal nerves}

Direct or indirect injury to the vagus nerve (C.N. X) or its branches, specifically the recurrent and superior laryngeal nerves, can occur during dissection around the carotid sheath. This is mostly due to the traction on the main trunk of the nerve, or lack of identification of the nerve during neck dissection, or placement of haemostatic clips to control haemorrhage during surgery. Unilateral true vocal cord paralysis, in the median or paramedian position, is the result of injury to the recurrent laryngeal nerve, and is generally well tolerated due to compensation from the intact contralateral vocal cord. However, mild to moderate hoarseness and diminished cough efforts are commonly experienced by patients. This problem becomes even more concerning in cases of bilateral injury when upper airway obstruction may result.

Injury to the branches of the superior laryngeal nerve can occur during dissection around the superior thyroid branch of the external carotid artery. This may result in minor swallowing difficulties due to decreased sensation at the laryngeal inlet, or decreased tensor capability of the true vocal cord. Early fatigability and decreased ability to phonate high pitched sounds may seriously affect professional vocalists or public speakers.

Direct laryngoscopy alone, or in combination with motor speech evaluation, and a high index of suspicion, can all assist in the accurate diagnosis of these neurologic injuries. Prevention remains the best management, and patients who depend on their voice professionally, require a detailed consultation and evaluation before and after surgery.

\section{Sympathetic trunk}

Disruption of the sympathetic trunk nerve fibers may cause ipsilateral Horner's syndrome. This is usually due to a surgical dissection that extends too far medially behind the carotid sheath. Horner's syndrome involves 
blepharoptosis due to disruption of the innervation to Mueller's muscle, miosis or pupillary constriction, anhidrosis with lack of perspiration of the forehead skin, apparent enophthalmos, and vascular dilation ipsilateral to the injury. Although the physical findings are pathognomonic for the diagnosis of Horner's syndrome, the clinical presentation can be occult and often variable. In addition, since Horner's syndrome findings may be due to variety of other factors, such as metastasis or vascular injuries, early recognition is of high importance $[\underline{2}, \underline{50}]$.

\section{CONCLUSIONS}

1. The early complications associated with oncologic surgery for oral cancer are the similar to other surgical procedures. The potential long-term complications however are quite challenging for the oncologic team as well as the patient who survives oral cancer, primarily due to the highly specialized regional tissues involved in the surgical field.
2. Some of these complications as evident above can be anticipated mainly due to the nature of the procedures involved for eradication of cancer in the highly specialized head and neck region.

3. It is of paramount importance for the oncology team to discuss possible complications in great detail and appropriately prepare the cancer patent.

4. It is of even greater importance to recognize and avoid those potential complications that would impact the patient's quality of life by strict adherence to basic surgical principles and in depth knowledge of the complex regional anatomy.

\section{ACKNOWLEDGMENTS AND DISCLOSURE STATEMENTS}

The author reports no conflicts of interest related to this study.

\section{REFERENCES}

1. Johnson N. Global Epidemiology. In: Shah JP, Johnson NW, Batsakis JG, editors. Oral Cancer. London: Martin Dunitz Publication; 2003. p. 7-22.

2. Kim DD, Ord RA. Complications in the treatment of head and neck cancer. Oral Maxillofac Surg Clin North Am. 2003 May;15(2):213-27. [Medline: 18088676] [doi: 10.1016/S1042-3699(02)00100-0]

3. Shah JP, Candela FC, Poddar AK. The patterns of cervical lymph node metastases from squamous carcinoma of the oral cavity. Cancer. 1990 Jul 1;66(1):109-13. [Medline: 2354399]

4. Triedman LJ. Complications of radical surgery for head and neck cancer- their prevention, recognition, and management. R I Med J. 1968 May;51(5):332-6. [Medline: 5240621]

5. Kerawala CJ. Complications of head and neck cancer surgery - prevention and management. Oral Oncol. 2010 Jun;46(6):433-5. [Medline: 20435509] [doi: 10.1016/j.oraloncology.2010.03.013]

6. Slaughter DP, Southwick HW, Smejkal W. Field cancerization in oral stratified squamous epithelium; clinical implications of multicentric origin. Cancer. 1953 Sep;6(5):963-8. [Medline: 13094644] [doi: 10.1002/1097-0142(195309)6:5<963::AID-CNCR2820060515>3.0.CO;2-Q]

7. Batsakis JG. Clinical pathology of oral cancer. In: Shah JP, Johnson NW, Batsakis JG, editors. Oral Cancer. London: Martin Dunitz Publication; 2003. p. 77-129.

8. Looser KG, Shah JP, Strong EW. The significance of "positive" margins in surgically resected epidermoid carcinomas. Head Neck Surg. 1978 Nov-Dec;1(2):107-11. [Medline: 755803] [doi: 10.1002/hed.2890010203]

9. Woolgar JA, Triantafyllou A. A histopathological appraisal of surgical margins in oral and oropharyngeal cancer resection specimens. Oral Oncol. 2005 Nov;41(10):1034-43. Epub 2005 Aug 29. [Medline: 16129652] [doi: 10.1016/j.oraloncology.2005.06.008]

10. Byers RM, Bland KI, Borlase B, Luna M. The prognostic and therapeutic value of frozen section determinations in the surgical treatment of squamous carcinoma of the head and neck. Am J Surg. 1978 Oct;136(4):525-8. [Medline: 707736] [doi: 10.1016/0002-9610(78)90275-1]

11. Ferlito A, Partridge M, Brennan J, Hamakawa H. Lymph node micrometastases in head and neck cancer: a review. Acta Otolaryngol. 2001 Sep;121(6):660-5. Review. [Medline: 11678163] [doi: 10.1080/00016480152583584]

12. Ferlito A, Shaha AR, Rinaldo A. The incidence of lymph node micrometastases in patients pathologically staged N0 in cancer of oral cavity and oropharynx. Oral Oncol. 2002 Jan;38(1):3-5. Review. [Medline: 11755814] [doi: 10.1016/S1368-8375(01)00037-9]

13. el-Naggar AK, Lai S, Luna MA, Zhou XD, Weber RS, Goepfert H, Batsakis JG. Sequential p53 mutation analysis of preinvasive and invasive head and neck squamous carcinoma. Int J Cancer. 1995 Jun 22;64(3):196-201. [Medline: 7622308] [doi: 10.1002/ijc.2910640309] 
14. Genden EM, Ferlito A, Bradley PJ, Rinaldo A, Scully C. Neck disease and distant metastases. Oral Oncol. 2003 Apr;39(3):207-12. Review. [Medline: 12618192] [doi: 10.1016/S1368-8375(02)00049-0]

15. Rubin Grandis J, Melhem MF, Gooding WE, Day R, Holst VA, Wagener MM, Drenning SD, Tweardy DJ. Levels of TGFalpha and EGFR protein in head and neck squamous cell carcinoma and patient survival. J Natl Cancer Inst. 1998 Jun 3;90(11):824-32. [Medline: 9625170] [doi: 10.1093/jnci/90.11.824] [FREE Full Text]

16. Takes RP, Baatenburg De Jong RJ, Alles MJ, Meeuwis CA, Marres HA, Knegt PP, De La Riviere GB, De Wilde PC, Mooi WJ, Hermans J, Van Krieken JH. Markers for nodal metastasis in head and neck squamous cell cancer. Arch Otolaryngol Head Neck Surg. 2002 May;128(5):512-8. [Medline: 12003581] [FREE Full Text]

17. Andersen PE, Warren F, Spiro J, Burningham A, Wong R, Wax MK, Shah JP, Cohen JI. Results of selective neck dissection in management of the node-positive neck. Arch Otolaryngol Head Neck Surg. 2002 Oct;128(10):1180-4. [Medline: 12365890] [FREE Full Text]

18. Calhoun KH, Fulmer P, Weiss R, Hokanson JA. Distant metastases from head and neck squamous cell carcinomas. Laryngoscope. 1994 Oct;104(10):1199-205. [Medline: 7934588] [doi: 10.1288/00005537-199410000-00003]

19. Kligerman J, Lima RA, Soares JR, Prado L, Dias FL, Freitas EQ, Olivatto LO. Supraomohyoid neck dissection in the treatment of T1/T2 squamous cell carcinoma of oral cavity. Am J Surg. 1994 Nov;168(5):391-4. [Medline: 7977957] [doi: 10.1016/S0002-9610(05)80082-0]

20. Medina JE, Byers RM. Supraomohyoid neck dissection: rationale, indications, and surgical technique. Head Neck. 1989 Mar-Apr;11(2):111-22. [Medline: 2722487] [doi: 10.1002/hed.2880110203]

21. Grégoire V, Bol A, Geets X, Lee J. Is PET-based treatment planning the new standard in modern radiotherapy? The head and neck paradigm. Semin Radiat Oncol. 2006 Oct;16(4):232-8. Review. [Medline: 17010906] [doi: 10.1016/j.semradonc.2006.04.006]

22. Schwartz DL, Rajendran J, Yueh B, Coltrera M, Anzai Y, Krohn K, Eary J. Staging of head and neck squamous cell cancer with extended-field FDG-PET. Arch Otolaryngol Head Neck Surg. 2003 Nov;129(11):1173-8. [Medline: 14623746] [doi: 10.1001/archotol.129.11.1173] [FREE Full Text]

23. Kolokythas A, Fernandes RP, Ord R. A non-lip-splitting double mandibular osteotomy technique applied for resection of tumors in the parapharyngeal and pterygomandibular spaces. J Oral Maxillofac Surg. 2007 Mar;65(3):566-9. [Medline: 17307611] [doi: 10.1016/j.joms.2005.06.025]

24. Pearlman NW. Treatment outcome in recurrent head and neck cancer. Arch Surg. 1979 Jan;114(1):39-42. [Medline: 758876]

25. Grandi C, Mingardo M, Guzzo M, Licitra L, Podrecca S, Molinari R. Salvage surgery of cervical recurrences after neck dissection or radiotherapy. Head Neck. 1993 Jul-Aug;15(4):292-5. [Medline: $\underline{\text { 8360049] [doi: 10.1002/hed.2880150404] }}$

26. Krol BJ, Righi PD, Paydarfar JA, Cheng ET, Smith RM, Lai DC, Bhargava V, Piccirillo JF, Hayes JT, Lue AJ, Scher RL, Weisberger EC, Wilson KM, Tran LE, Rizk N, Pellitteri PK, Terris DJ. Factors related to outcome of salvage therapy for isolated cervical recurrence of squamous cell carcinoma in the previously treated neck: a multi-institutional study. Otolaryngol Head Neck Surg. 2000 Oct;123(4):368-76. [Medline: 11020170] [doi: 10.1067/mhn.2000.107680]

27. Bonner JA, Harari PM, Giralt J, Azarnia N, Shin DM, Cohen RB, Jones CU, Sur R, Raben D, Jassem J, Ove R, Kies MS, Baselga J, Youssoufian H, Amellal N, Rowinsky EK, Ang KK. Radiotherapy plus cetuximab for squamous-cell carcinoma of the head and neck. N Engl J Med. 2006 Feb 9;354(6):567-78. [Medline: 16467544] [doi: 10.1056/NEJMoa053422]

28. Forastiere A, Koch W, Trotti A, Sidransky D. Head and neck cancer. N Engl J Med. 2001 Dec 27;345(26):1890-900. Review. Erratum in: N Engl J Med 2002 Mar 7;346(10):788. [Medline: 11756581] [doi: 10.1056/NEJMra001375]

29. Robert F, Ezekiel MP, Spencer SA, Meredith RF, Bonner JA, Khazaeli MB, Saleh MN, Carey D, LoBuglio AF, Wheeler RH, Cooper MR, Waksal HW. Phase I study of anti--epidermal growth factor receptor antibody cetuximab in combination with radiation therapy in patients with advanced head and neck cancer. J Clin Oncol. 2001 Jul 1;19(13):3234-43. [Medline: 11432891]

30. LaBlance GR, Kraus K, Steckol KF. Rehabilitation of swallowing and communication following glossectomy. Rehabil Nurs. 1991 Sep-Oct;16(5):266-70. Review. [Medline: 1891651]

31. Massengill R Jr, Maxwell S, Pickrell K. An analysis of articulation following partial and total glossectomy. J Speech Hear Disord. 1970 May;35(2):170-3. [Medline: 5442338]

32. Pauloski BR, Logemann JA, Colangelo LA, Rademaker AW, McConnel FM, Heiser MA, Cardinale S, Shedd D, Stein D, Beery Q, Myers E, Lewin J, Haxer M, Esclamado R. Surgical variables affecting speech in treated patients with oral and oropharyngeal cancer. Laryngoscope. 1998 Jun;108(6):908-16. [Medline: 9628509] [doi: 10.1097/00005537-199806000-00022]

33. Pauloski BR, Logemann JA, Rademaker AW, McConnel FM, Heiser MA, Cardinale S, Shedd D, Lewin J, Baker SR, Graner D, et al. Speech and swallowing function after anterior tongue and floor of mouth resection with distal flap reconstruction. J Speech Hear Res. 1993 Apr;36(2):267-76. [Medline: 8487519]

34. Logemann JA. The role of the speech language pathologist in the management of dysphagia. Otolaryngol Clin North Am. 1988 Nov;21(4):783-8. Review. [Medline: 3054726] 
35. Rentschler GJ, Mann MB. The effects of glossectomy on intelligibility of speech and oral perceptual discrimination. J Oral Surg. 1980 May;38(5):348-54. [Medline: 6928933]

36. Curtis DA, Plesh O, Miller AJ, Curtis TA, Sharma A, Schweitzer R, Hilsinger RL, Schour L, Singer M. A comparison of masticatory function in patients with or without reconstruction of the mandible. Head Neck. 1997 Jul;19(4):287-96. [Medline: 9213107] [doi: 10.1002/(SICI)1097-0347(199707)19:4<287::AID-HED7>3.0.CO;2-X]

37. Urken ML, Buchbinder D, Weinberg H, Vickery C, Sheiner A, Parker R, Schaefer J, Som P, Shapiro A, Lawson W, et al. Functional evaluation following microvascular oromandibular reconstruction of the oral cancer patient: a comparative study of reconstructed and nonreconstructed patients. Laryngoscope. 1991 Sep;101(9):935-50. [Medline: 1886442] [doi: 10.1288/00005537-199109000-00004]

38. Urken ML, Weinberg H, Vickery C, Buchbinder D, Lawson W, Biller HF. Oromandibular reconstruction using microvascular composite free flaps. Report of 71 cases and a new classification scheme for bony, soft-tissue, and neurologic defects. Arch Otolaryngol Head Neck Surg. 1991 Jul;117(7):733-44. [Medline: 1863438]

39. Vaughan ED. An analysis of morbidity following major head and neck surgery with particular reference to mouth function. J Maxillofac Surg. 1982 Aug;10(3):129-34. [Medline: 6957515] [doi: 10.1016/S0301-0503(82)80027-1]

40. Vaughan ED, Bainton R, Martin IC. Improvements in morbidity of mouth cancer using microvascular free flap reconstructions. J Craniomaxillofac Surg. 1992 Apr;20(3):132-4. [Medline: 1613109] [doi: 10.1016/S1010-5182(05)80095-2]

41. Buchbinder D, Currivan RB, Kaplan AJ, Urken ML. Mobilization regimens for the prevention of jaw hypomobility in the radiated patient: a comparison of three techniques. J Oral Maxillofac Surg. 1993 Aug;51(8):863-7. [Medline: 8336223] [doi: 10.1016/S0278-2391(10)80104-1]

42. Dijkstra PU, Kalk WW, Roodenburg JL. Trismus in head and neck oncology: a systematic review. Oral Oncol. 2004 Oct;40(9):879-89. Review. [Medline: 15380165] [doi: 10.1016/j.oraloncology.2004.04.003]

43. Ichimura K, Tanaka T. Trismus in patients with malignant tumours in the head and neck. J Laryngol Otol. 1993

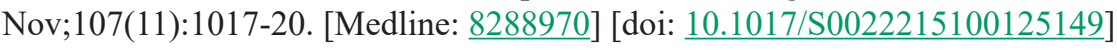

44. Dijkstra PU, Huisman PM, Roodenburg JL. Criteria for trismus in head and neck oncology. Int J Oral Maxillofac Surg. 2006 Apr;35(4):337-42. Epub 2005 Nov 8. [Medline: 16280237] [doi: 10.1016/j.ijom.2005.08.001]

45. Hooley R, Levin H, Flores TC, Wheeler T, Steigeo E: Predicting Postoperative Head and Neck Complications Using Nutritional Assessment. Arch Otolaryngol 1983;109(2):83-85. [FREE Full Text]

46. Picker H, Bichler E. Nutritional and immunological investigations in head and neck cancer patients before and after therapy. Arch Otorhinolaryngol. 1985;242(2):149-53. [Medline: 2415099] [doi: 10.1007/BF00454414]

47. Cappiello J, Piazza C, Nicolai P. The spinal accessory nerve in head and neck surgery. Curr Opin Otolaryngol Head Neck Surg. 2007 Apr;15(2):107-11. Review. [Medline: 17413412] [doi: 10.1097/MOO.0b013e3280523ac5]

48. Saunders JR Jr, Hirata RM, Jaques DA. Considering the spinal accessory nerve in head and neck surgery. Am J Surg. 1985 Oct;150(4):491-4. [Medline: 4051114] [doi: 10.1016/0002-9610(85)90161-8]

49. Dingman RO, Grabb WC. Surgical anatomy of the mandibular ramus of the facial nerve based on the dissection of 100 facial halves. Plast Reconstr Surg Transplant Bull. 1962 Mar;29:266-72. [Medline: 13886490] [doi: 10.1097/00006534-196203000-00005]

50. Schauber MD, Fontenelle LJ, Solomon JW, Hanson TL. Cranial/cervical nerve dysfunction after carotid endarterectomy. J Vasc Surg. 1997 Mar;25(3):481-7. [Medline: 9081129] [doi: 10.1016/S0741-5214(97)70258-1]

To cite this article:

Kolokythas A. Long-Term Surgical Complications in the Oral Cancer Patient: a Comprehensive Review. Part I.

J Oral Maxillofac Res 2010 (Jul-Sep);1(3):e1

URL: http://www.ejomr.org/JOMR/archives/2010/3/e1/e1ht.pdf

doi: $10.5037 /$ jomr.2010.1301

Copyright (C) Kolokythas A. Accepted for publication in the JOURNAL OF ORAL \& MAXILLOFACIAL RESEARCH (http://www.ejomr.org), 4 July 2010.

This is an open-access article, first published in the JOURNAL OF ORAL \& MAXILLOFACIAL RESEARCH, distributed under the terms of the Creative Commons Attribution-Noncommercial-No Derivative Works 3.0 Unported License, which permits unrestricted non-commercial use, distribution, and reproduction in any medium, provided the original work and is properly cited. The copyright, license information and link to the original publication on (http://www.ejomr.org) must be included. 